\title{
1,1,3,3-テトラメトキシプロパンの加水分解とその生成物 マロンジアルデヒドの吸光光度定量
}

\author{
今井 弘 ${ }^{\circledR}$, 荒井 善一 ${ }^{*}$
}

(1990 年 10 月 3 日受理)

1,1,3,3-テトラメトキシプロパン (TMP) の加水分解と, その生成物であるマロンジアルデヒド (MDA) をチオバルビツール酸（TBA）法によって吸光光度定量する条件を検討した．TMPは pH 1 にした水 溶液中で $25^{\circ} \mathrm{C}$ ，5 時間放置すると，完全に加水分解した。 その速度定数は $2.78 \times 10^{-4} \mathrm{~s}^{-1}$ であった。 得られた MDA は $\mathrm{pH} 0$ 2 において TBA と定量的に反応し, $532 \mathrm{~nm}$ に吸収極大をもつトリメチン色 素が生成した. MDA が $0.5 \times 10^{-6} \mathrm{M}$ から $6.5 \times 10^{-6} \mathrm{M}$ までの範囲で, 濃度と吸光度との間に比例関 係が認められ，そのモル吸光係数は $532 \mathrm{~nm}$ の波長で $1.4 \times 10^{5} 1 \mathrm{~mol}^{-1} \mathrm{~cm}^{-1}$ であった。

\section{1 緒言}

過酸化脂質はチオバルビツール酸（TBA）によって 発色することが Kohn らによって報告されている1).そ の後の研究によれば,この発色はマロンジアルデヒド (MDA）との反応であることが分かってきた2)。この MDA は脂肪酸や食品の過酸化反応によって生じた脂質 過酸化物の分解生成物であると言われていたが3)4), 最 近になって, MDA は脂質過酸化物として遊離の状態で 存在するのではなく，脂質過酸化物の加熱分解によって 生じることが分かってきた5).一方，MDA はデオキシ リポースとヒドロキシラジカル $(\cdot \mathrm{OH})$ との反応によ っても発生する.

著者らは過酸化水素から· $\mathrm{OH}$ の発生を促進させる金 属錯体を探求するために，精度並びに再現性に優れた · $\mathrm{OH}$ の定量条件を確立する必要性が生じてきた. $\mathrm{OH}$ はデオキシリポースと反忍して MDAを生成する。こ の MDA は TBA と反忘してトリメチン色素になるの でこの色素の吸光度を测定することによって・OH を 定量することができる．既に，この方法は· $\mathrm{OH}$ の検出 に応用されているが(i)，既知の条件ではトリメチン色素 の安定性が悪いので再現性に乏しく，更に検量線の作成 が困難である。このような点を改良するために，TBA による MDAの㳬量条件を詳細に検討することにし た。

\footnotetext{
* 関两大学:学部教養化学: 564 大阪府吹田市山手町
}

MDA の定量において, 困難な問題は高純度の MDA が得られないこと, 又その水溶液の安定性は 48 時間以 内3)であることなどのために，検量線を作成する標準物 質を得難いことである，そこで，著者らは安定で，しか も容易に入手することができる 1,1,3,3-テトラメトキシ プロパン (TMP) を標準物質として使用することにし た.

TMP は酸性水溶液中で式(1)のように加水分解し て, TMP と等モルの MDAを生成する.

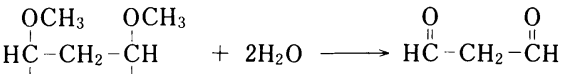

$$
\begin{aligned}
& \begin{array}{lll}
\mathrm{OCH}_{3} & \mathrm{OCH}_{3} & +4 \mathrm{CH}_{3} \mathrm{OH}
\end{array} \\
& \text { (TMP) (MDA) }
\end{aligned}
$$

生成した MDA は酸性溶液中で, 式( 2 )のように TBA と反応してトリメチン色素を生成する7).

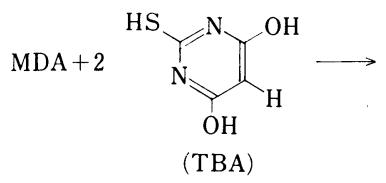

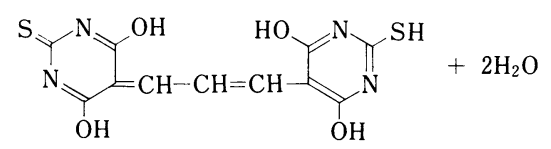


本実験では, TMP の加水分解に対する $\mathrm{pH}$ の影響を 調べた後, 加水分解速度定数を測定し, 続いてトリメチ ン色素を生成させるための最適条件を決定して MDA の吸光光度定量法を確立することを目的にした。

\section{2 実験}

\section{$\mathbf{2} \cdot \mathbf{1}$ 試 薬}

1,1,3,3-テトラメトキシプロパン（TMP）溶液: 和光 純薬工業一級品の TMP を $16 \mathrm{~mm} \mathrm{Hg}$ で減圧蒸留して $68^{\circ} \mathrm{C}$ の留分を採取し，この $50 \mathrm{mg}$ を蒸留水に溶かして $100 \mathrm{ml}$ とし, $3 \times 10^{-3} \mathrm{M}$ の溶液を調製した。

チオバルビツール酸 (TBA) 溶液 : 和光純薬工業特級 品の TBA $5 \mathrm{~g}$ を $5 \times 10^{-2} \mathrm{M}$ 水酸化ナトリウム溶液 500 $\mathrm{ml}$ に溶かし， $6.9 \times 10^{-2} \mathrm{M}$ の溶液を調製した。

緩衝溶液: $\mathrm{pH} 2$ 2 5 並びに $\mathrm{pH} 7$ 8 はそれぞれ Clark-Lubs 並びに Walpole 緩衝溶液を用いた。

その他の試薬 : 和光純薬丁.業の特級品を用いた。

\section{$2 \cdot 2$ 装 置}

吸収スペクトル並びに吸光度は島津製 UV-365 型自 記分光光度計を用いて測定した。 又, $\mathrm{pH}$ は堀場製 F-8 型 $\mathrm{pH}$ メーターを用いて測定した。

\section{$2 \cdot 3$ 実験操作}

2・3・1 TMP の加水分解 任意の $\mathrm{pH}$ に調節した $(1 \sim 10) \times 10^{-5} \mathrm{M}$ の TMP 溶液を一定温度に保ち, 放 置時間に対する吸光度の変化から加水分解速度を調べ た。なお，吸光度は $245 \mathrm{~nm}$ の波長を用いて測定した。

2・3・2 MDA の定量 TMP を完全に加水分解し て得た MDA 溶液の $1 \mathrm{ml}$ を採取し,これに TBA 溶液 $12 \mathrm{ml}$ を加え, 更に $\mathrm{pH}$ を調節して全容を $15 \mathrm{ml}$ の試料 溶液とした。これを沸騰水中に 15 分間浸して発色させ た後，室温まで急冷する．これを適当な時間だけ放㯰し てから $532 \mathrm{~nm}$ の波長を用いて吸光度を測定した。

\section{3 結果と考察}

\section{3・1 MDA の吸収スペクトル}

TMP は酸性溶液中で徐々に加水分解して MDA が生 成する ${ }^{3)}$ 。そこで, 塭酸で $\mathrm{pH} 1$ にした TMP 溶液を室 温で 24 時間放置して加水分解させ, MDA が生成した 溶液の吸収スペクトルを测定した。

Fig. 1に示したように，MDAは245 nm に吸収極大 が現れた。この吸収波長は, Philpotが測定した值とよ く一致した ${ }^{3)}$. 一方, TMP は $210 \mathrm{~nm}$ より長波長側に は吸収が認められなかった。従って, TMP の加水分解

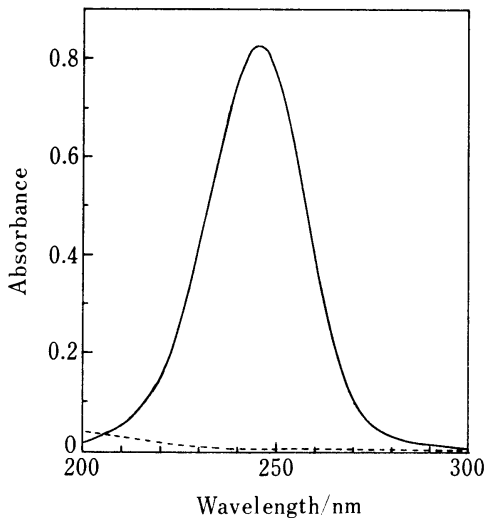

Fig. 1 Absorption spectra of malondialdehyde obtained by hydrolysis of TMP

TMP (=MDA) : $6.2 \times 10^{-5} \mathrm{M} ; \mathrm{pH}: 1 ;$ Standing time of TMP solution : $24 \mathrm{~h}$; - : spectrum of MDA; -.. : spectrum of TMP

は $245 \mathrm{~nm}$ の波長を用いて, 吸光度から追跡することに した。

\section{3 •2 TMP の加水分解に対する pH の影響}

TMP を完全に加水分解させるために，まず $\mathrm{pH}$ の影 響を調べた。その結果を Table 1 に示す.

$\mathrm{pH} 1$ にした TMP 溶液の吸光度は試料調製後 20 時 間放置したときの值と，24 時間後の傎が同じであった ことから，TMP の加水分解は 24 時間放置によって, ほぼ完了したものと考えられる. しかし, pH l よりも 高い $\mathrm{pH}$ の TMP 溶液の吸光度は時間と共に徐々に大 きくなり，24 時間放置後の吸光度は Table 1 に示した ような值になったことから，加水分解は完了していない ことを示している。このことから， $\mathrm{pH}$ が高くなるほ

Table 1 Effect of $\mathrm{pH}$ on hydrolysis of TMP

\begin{tabular}{ccc}
\hline $\mathrm{pH}$ & Absorbance & Percent hydrolysis \\
\hline 1 & 0.835 & 100 \\
2 & 0.656 & 78.6 \\
3 & 0.127 & 15.2 \\
5 & 0.015 & 1.8 \\
7 & 0.011 & 1.3 \\
8 & 0.006 & 0.7 \\
\hline
\end{tabular}

TMP : $6.2 \times 10^{-5} \mathrm{M}$; Temperature : $25^{\circ} \mathrm{C}$; Standing time of TMP solution : $24 \mathrm{~h}$; Wavelength : 245 $\mathrm{nm}$ 
ビ，加水分解は著しく遅くなることが分かった。

このような結果から，水に溶かしたTMP は徐々に加 水分解することが推察される。従って, 実験には使用時 に新しく調製した TMP 浴液を用いなければならないこ とが分かった。

次に，塩酸で $\mathrm{pH} 1$ にした水溶液中における TMP の 加水分解速度を測定した。 まず，TMPの濃度を (1.5 6.2) × $10^{-5} \mathrm{M}$ として $25^{\circ} \mathrm{C}$ における加水分解の 状況を時間の経過から調べた結果，Fig. 2のようになっ た。

TMP の加水分解は濃度に関係なく, 約 4 時間で完了 することが分かった。この曲線には一次反応速度式を適 用することができるので, この式から加水分解速度定数 を計算した。 その結果, 約 $2.7 \times 10^{-4} \mathrm{~s}^{-1}$ となった。

続いて，一定濃度の TMP について温度による加水分

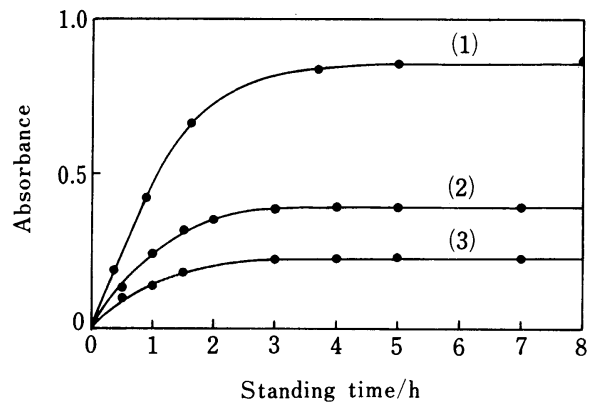

Fig. 2 Effect of standing time on hydrolysis of TMP

Wavelength : $245 \mathrm{~nm} ; \mathrm{pH}: 1$; Temperature : $25^{\circ} \mathrm{C}$; Concentration of TMP: (1) $6.20 \times 10^{-5} \mathrm{M}$, (2) $3.16 \times 10^{-5} \mathrm{M}$, (3) $1.58 \times 10^{-5} \mathrm{M}$

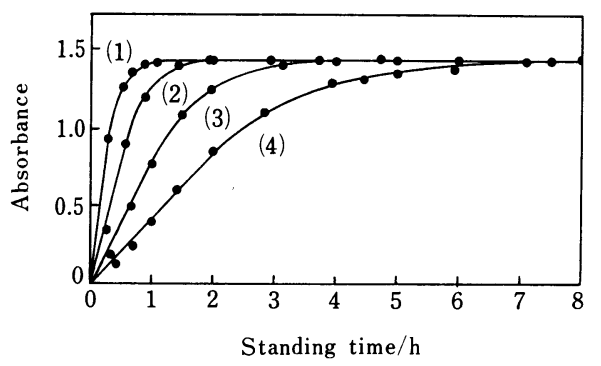

Fig. 3 Effect of temperature and standing time on hydrolysis of TMP

Wavelength : $245 \mathrm{~nm} ; \mathrm{pH}: 1$; Concentration of TMP : $1.0 \times 10^{-4} \mathrm{M}$; Temperature $\left({ }^{\circ} \mathrm{C}\right)$ : (1) 34.8 , (2) 30.7 , (3) 25.0 , (4) 21.0
Table 2 Rate constants of hydrolysis of TMP

\begin{tabular}{cc}
\hline Temperature $/ \mathrm{K}$ & Rate constant $/ 10^{-4} \mathrm{~s}^{-1}$ \\
\hline 294 & 1.58 \\
298 & 2.78 \\
304 & 6.88 \\
308 & 13.7 \\
\hline
\end{tabular}

TMP : $1.0 \times 10^{-4} ; \mathrm{pH}: 1$

解速度を調べた。 その結果を Fig. 3 に示す.

TMP の加水分解は約 $20^{\circ} \mathrm{C}$ において約 7 時間かかる が, 温度が高くなると, 著しく速くなり, 約 $35^{\circ} \mathrm{C}$ では 1 時間で完了した。

そこで，Fig. 3 に示した各曲線を Fig. 2 の場合と同 じように, 一次反応速度式を用いて加水分解速度定数を 計算すると, Table 2 のような值が得られた。

これによると， $35^{\circ} \mathrm{C}$ における TMP の加水分解速度 は $20^{\circ} \mathrm{C}$ のときの約 8.7 倍も大きくなることが分かっ た. Table 2 に示した速度定数を温度の逆数に対してア レニウスプロットして求めた活性化エネルギーは 114.0 $\mathrm{kJ} \mathrm{mol}^{-1}$ であった。

以上の結果に基づいて, 塩酸で $\mathrm{pH} 1$ にした TMP 溶 液を $25^{\circ} \mathrm{C}$ で約 5 時間放置して完全に加水分解し, 生成 した MDA の吸光度と濃度の関係を調べた結果, MDA の濃度が約 $1 \times 10^{-4} \mathrm{M}$ 以下では両者間に直線関係が認 められ，245 nm の波長におけるモル吸光係数は $1.4 \times 10^{4} \mathrm{l} \mathrm{mol}^{-1} \mathrm{~cm}^{-1}$ であった.

\section{3・3 TBA による MDA の定量}

TMP の加水分解によって, TMP と等モル生成する MDA を吸光光度定量するために, TBA と反応させて トリメチン赤色色素を生成する最適条件を調べた.

$2 \cdot 3 \cdot 2$ に述べた方法に基づいて, $\mathrm{pH} 1$ で発色させた トリメチン赤色色素の吸収極大は $532 \mathrm{~nm}$ に現れたの で，以下の実験ではこの波長を用いて吸光度を測定する ことにした。まず，種々の $\mathrm{pH}$ のもとで MDA と TBA を反忍させた. その結果を Fig. 4 に示す.

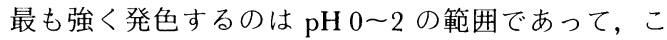
れよりも $\mathrm{pH}$ が高くなると発色し難くなり, 特に塩基 性側ではほとんど発色しなかった。このようなことか ら, 以下の実験では $\mathrm{pH} 1$ にして MDA と TBA を反忘 させることにした。

次に，放置時間に対する吸光度の安定性を検討した。 その結果を Table 3 に示す.

吸光度は 2 時間まで, 徐々に減少したが, それ以降 


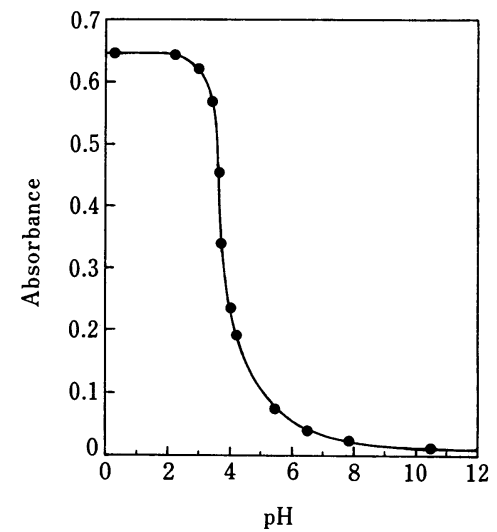

Fig. 4 Effect of $\mathrm{pH}$ on the reaction of TBA and MDA

Wavelength : $532 \mathrm{~nm}$; MDA : $4.25 \times 10^{-6} \mathrm{M}$; TBA : $5.5 \times 10^{-2} \mathrm{M}$; Standing time at room temperature : $30 \mathrm{~min}$

Table 3 Relationship between standing time and absorbance of trimethine coloring matter obtained from the reaction of MDA and TBA

\begin{tabular}{cc|cc}
\hline $\begin{array}{c}\text { Standing } \\
\text { time/min }\end{array}$ & Absorbance & $\begin{array}{c}\text { Standing } \\
\text { time/min }\end{array}$ & Absorbance \\
\hline 10 & 0.653 & 90 & 0.612 \\
25 & 0.642 & 120 & 0.604 \\
40 & 0.632 & 150 & 0.602 \\
60 & 0.620 & 180 & 0.598 \\
\hline
\end{tabular}

MDA : $4.25 \times 10^{-6} \mathrm{M}$; Temperature : $25^{\circ} \mathrm{C}$; Wavelength : $532 \mathrm{~nm}$

になると，測定誤差範曲程度の減少になった，従って， 加熱して発色させた試料を室温まで急冷した後，これを 2 時間放置してから吸光度を測定することにした。この ような条件のもとで, 吸光度の再現性は $0.8 \%$ の範囲内 であることが明らかになった。

以上の上うに決定した最適条件のもとで，MDAの濃 度と吸光度の関係から, $532 \mathrm{~nm}$ におけるモル吸光係数 を求めた結果, $1.4 \times 10^{5} 1 \mathrm{~mol}^{-1} \mathrm{~cm}^{-1}$ であって, 245 $\mathrm{nm}$ におけるそれよりも10 倍大きくなった。このこと から，MDA の最大吸収波躴である $245 \mathrm{~nm}$ を用いるよ りも，TBA との反心はよって得られたトリメチン色素 の最大吸収波長 $532 \mathrm{~nm}$ を用いたほうが, 高い感度で MDA を定量できることが分かった。

\section{3•4 MDA 定量の最適操作法と検量線の作成}

脂質過酸化物の加熱分解又はデオキシリポースと ·OH の反応によって生じる MDA は次のようにして TBA と反态させると，高い感度で MDA を定量するこ とができる。

MDA 溶液の $1 \mathrm{ml}$ を採取しこれに約 $7 \times 10^{-2} \mathrm{M}$ の $\mathrm{TBA}$ 溶液 $12 \mathrm{ml}$ を加え，更に $\mathrm{pH} 1$ になるように塩酸 を加え，全容を $15 \mathrm{ml}$ にする．次に，この溶液を沸騰 水中に 15 分間浸して発色させた後，室温まで急冷し， 続いて 2 時間放置してから $532 \mathrm{~nm}$ の波長を用いて吸光 度を測定する。

なお，MDA を吸光光度定量するために，検量線は次 のような方法で作成する.

加水分解によって等モルの MDA を生成する TMP 溶液を塩酸で $\mathrm{pH} 1$ に調節し，これを $25^{\circ} \mathrm{C} て ゙ 5$ 時間放 置して加水分解させると, MDA が生成する。これを上 述と同じ操作法で発色させると，MDAの濃度が $0.5 \times 10^{-6} \mathrm{M}$ から $6.5 \times 10^{-6} \mathrm{M}$ までの範囲において, 両者間に比例関係が認められ，原点を通る直線が得られ る.

\section{文献}

1) H. Kohn, M. Liversedge: J. Pharmacol. Exptl. Therap., 82, 292 (1944).

2) S. Patton, G. Kurtz: J. Dairy Sci., 34, 669 (1951).

3) J. St. L. Philpot: Radiat. Res. Suppl., 3, 55 (1963).

4) 大柳善彦: “活性酸素と病気”, p. 126 (1989),(化 学同人).

5）松尾光芳, 嵯峨井勝, 吉川敏一訳: “フリーラジカ ルと生体”, p. 180 (1988), (学会出版センター).

6) B. Halliwell, J. M. C. Gutteridge: Molec. Aspects Med., 8, 89 (1985).

7) Z. A. Placer, L. L. Cushman, B. C. Johnson : Anal. Biochem., 16, 359 (1966).

Hydrolysis of 1,1,3,3-tetramethoxypropane and spectrophotometric determination of its product, malondialdehyde. Hiromu Imai and Zenichi Arai (Faculty of Engineering, Kansai University, Yamate-cho, Suita-shi, Osaka 564)

The determination of malondialdehyde (MDA) which is an end product of the hydrolysis of 1,1,3,3-tetramethoxypropane (TMP) was investigated spectrophotometrically. 
TMP in aqueous solution, adjusted $\mathrm{pH}$ to 1 , was completely hydrolyzed, after $5 \mathrm{~h}$ at $25^{\circ} \mathrm{C}$. The rate constant of hydrolysis was $2.78 \times 10^{-4} \mathrm{~s}^{-1}$. The determination of MDA is carried out as follows: take $1 \mathrm{ml}$ of a sample solution, which contain less than $6.5 \times 10^{-6} \mathrm{M}$ of MDA, add $12 \mathrm{ml}$ of a solution, which has $6.9 \times 10^{-2} \mathrm{M}$ thiobarbituric acid dissolved in $5 \times 10^{-2} \mathrm{M}$ sodium hydroxide; after adjusting $\mathrm{pH}$ to 1 with hydrochloric acid, dilute this solution with water to a $15 \mathrm{ml}$; put the sample in boiling water for $15 \mathrm{~min}$ and after cooling for $2 \mathrm{~h}$ at room temperature, read the absorbance value. The calibration curve was prepared from MDA obtained by the hydrolysis of TMP. The linear relationship between the concentration of MDA and the absorbance was in the range of 0.5 $\times 10^{-6} \mathrm{M}$ to $6.5 \times 10^{-6} \mathrm{M}$. The molar extinction coefficient was $1.4 \times 10^{5} \mathrm{lmol}^{-1} \mathrm{~cm}^{-1}$ at the wavelength of $532 \mathrm{~nm}$. This procedure can be applied to the determination of hydroxy radical.

(Received October 3, 1990)

\section{Keyword phrases}

hydrolysis of 1,1,3,3-tetramethoxypropane; reaction of thiobarbituric acid with malondialdehyde; determination of malondialdehyde. 